\title{
Erratum to: Recovery of visual function in patient with melanoma-associated retinopathy treated with surgical resection and interferon-beta
}

\author{
Shuichi Yamamoto $\cdot$ Junko Hanaya • \\ Kentaro Mera $\cdot$ Kazunori Miyata
}

Published online: 12 March 2013

(C) Springer-Verlag Berlin Heidelberg 2013

\section{Erratum to: Doc Ophthalmol (2012) 124:143-147 DOI 10.1007/s10633-012-9313-6}

The original article published in Volume 124, Issue 2 includes an errors which is corrected as below:

On page 144, the sentence "Immunohistochemistry with the patient's serum on rat retinas showed specific staining of the inner nuclear layer." should be cited with the following reference.
The online version of the original article can be found under doi:10.1007/s10633-012-9313-6.

S. Yamamoto $(\square)$

Department of Ophthalmology and Visual Science,

Chiba University Graduate School of Medicine,

1-8-1 Inohana, Chuo-ku, Chiba 260-0856, Japan

e-mail: shuyama@faculty.chiba-u.jp

J. Hanaya

Kagoshima Miyata Eye Clinic, Kagoshima, Japan

K. Mera

Department of Dermatology, Kagoshima University

Graduate School of Medicine and Dental Science,

Kagoshima, Japan

K. Miyata

Miyata Eye Hospital, Miyakonojo, Japan
Hanaya J, Nakamura Y, Nejima R, Miyata K, Mera K, Ohguro H, Yamamoto S (2011) Case report of melanomaassociated retinopathy associated with positive autoantibodies against retinal bipolar cells. Nippon Ganka Gakkai Zasshi (J Jpn Ophthalmol Soc) 115:541-546. 